\title{
Convergent Approach for Commercial Synthesis of Gefitinib and \\ Erlotinib
}

Venkateshappa Chandregowda, Gudapati Venkateswara Rao, Goukanapalli

Chandrasekara Reddy*

Vittal Mallya Scientific Research Foundation, P. B. No. 406, K. R. Road, Bangalore560004, India.

E-mail: gcreddy@vmsrf.org

\section{Supporting Information}

1. ${ }^{1} \mathrm{H}$ NMR Spectra

2. Selected HRMS and MS Spectra

3. Selected HPLC Spectra 


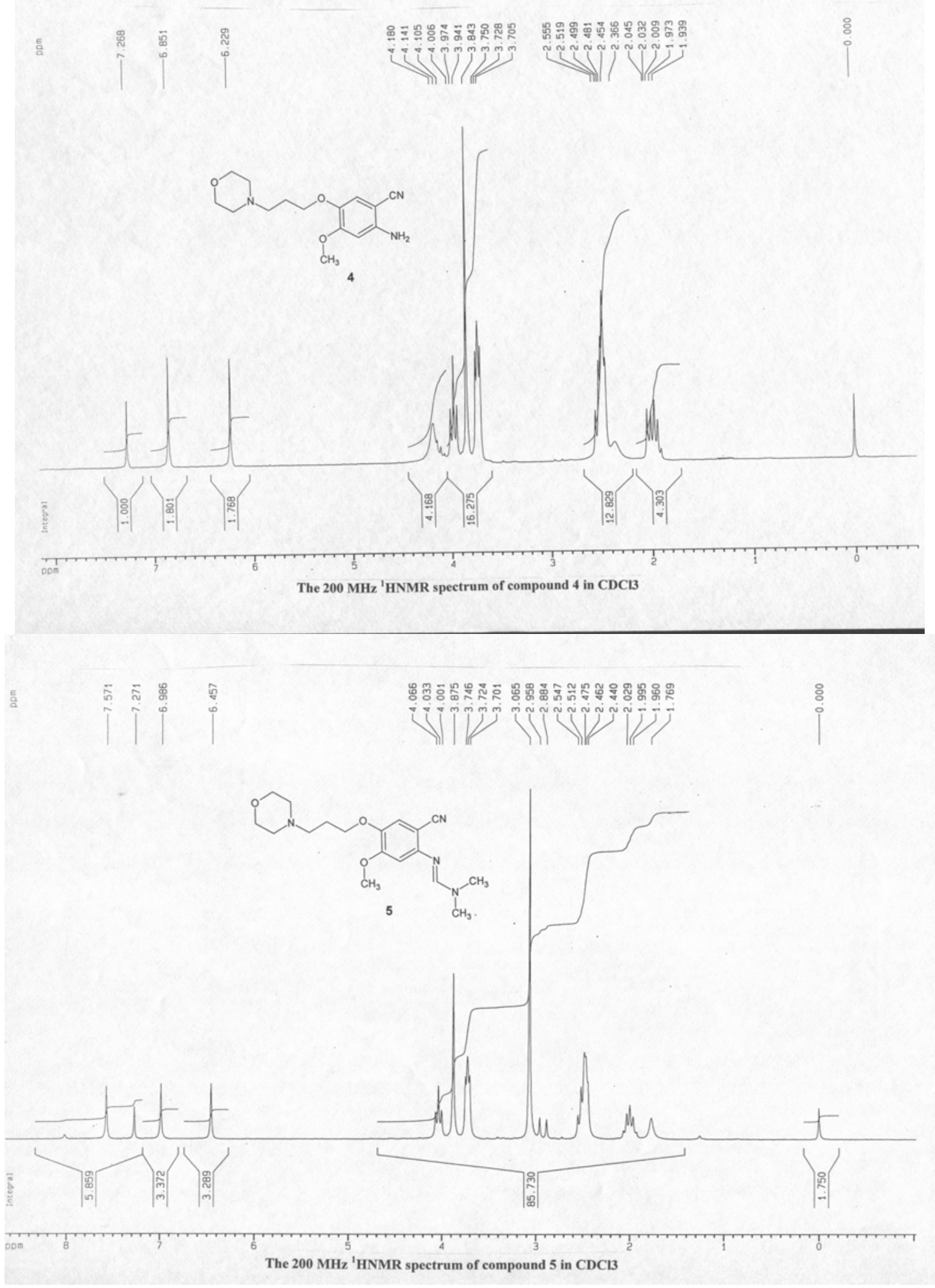

$\mathrm{S}_{2}$ 


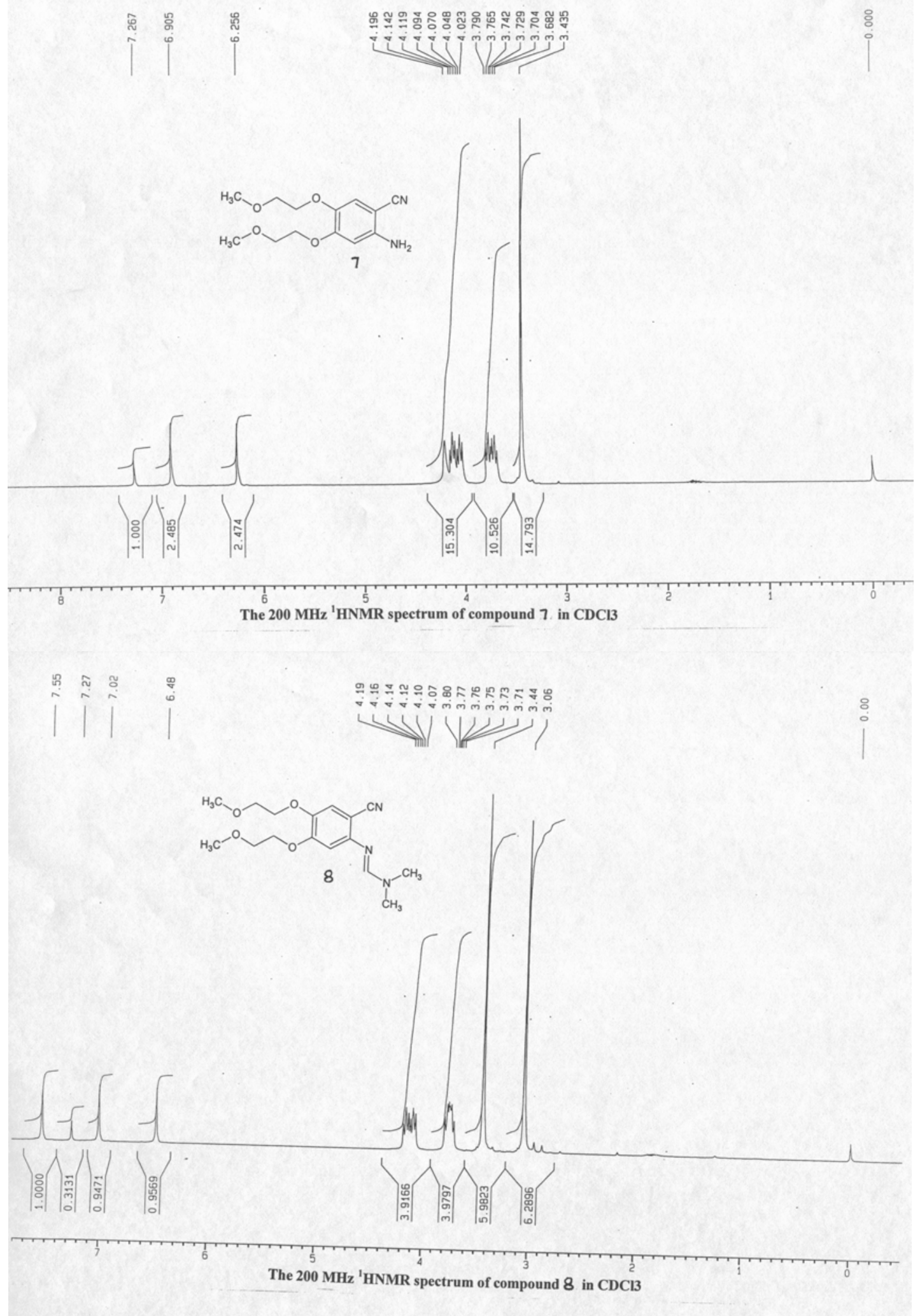




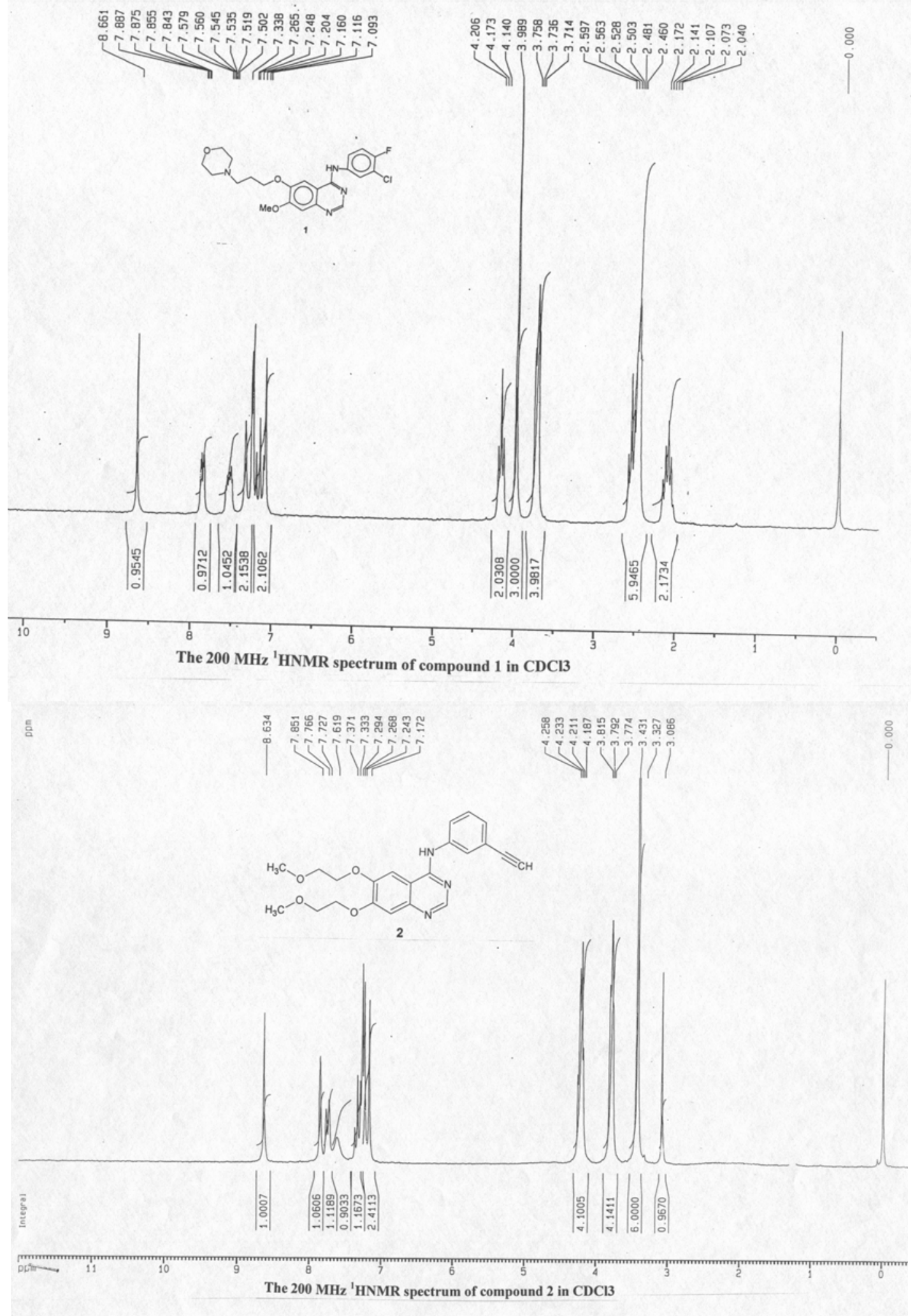




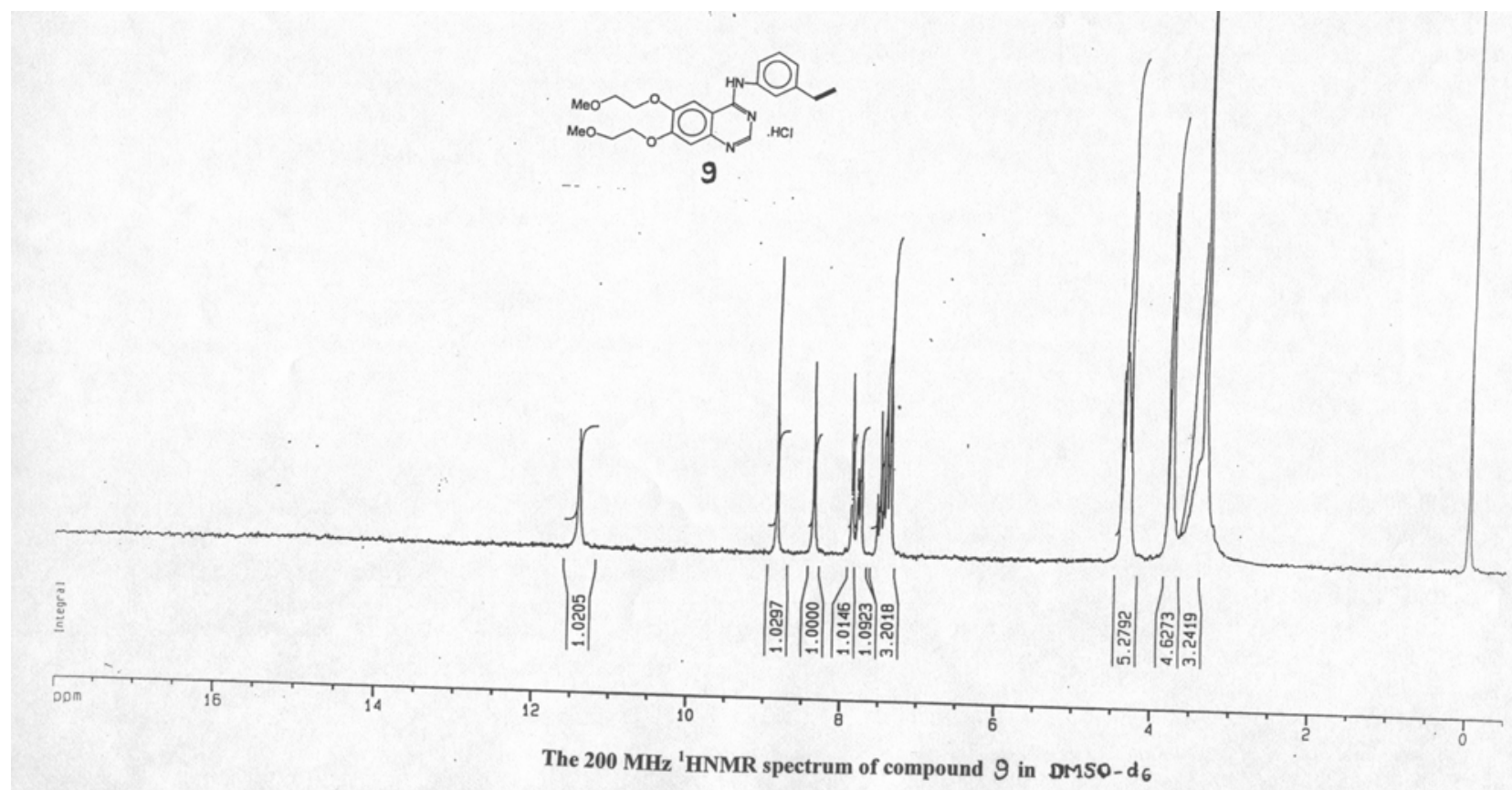

$\mathrm{S}_{5}$ 


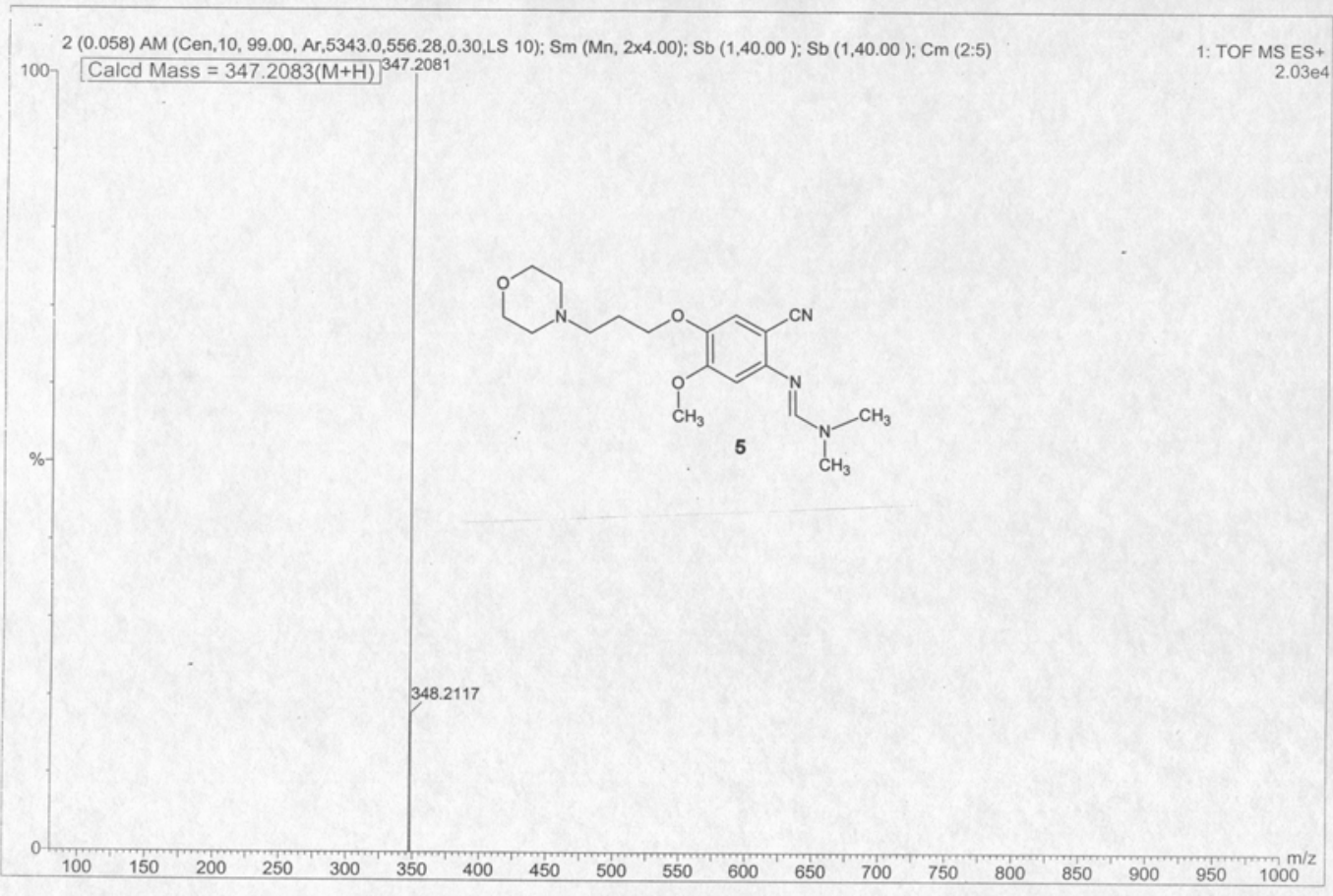

High resolution mass spectrum of compound 5

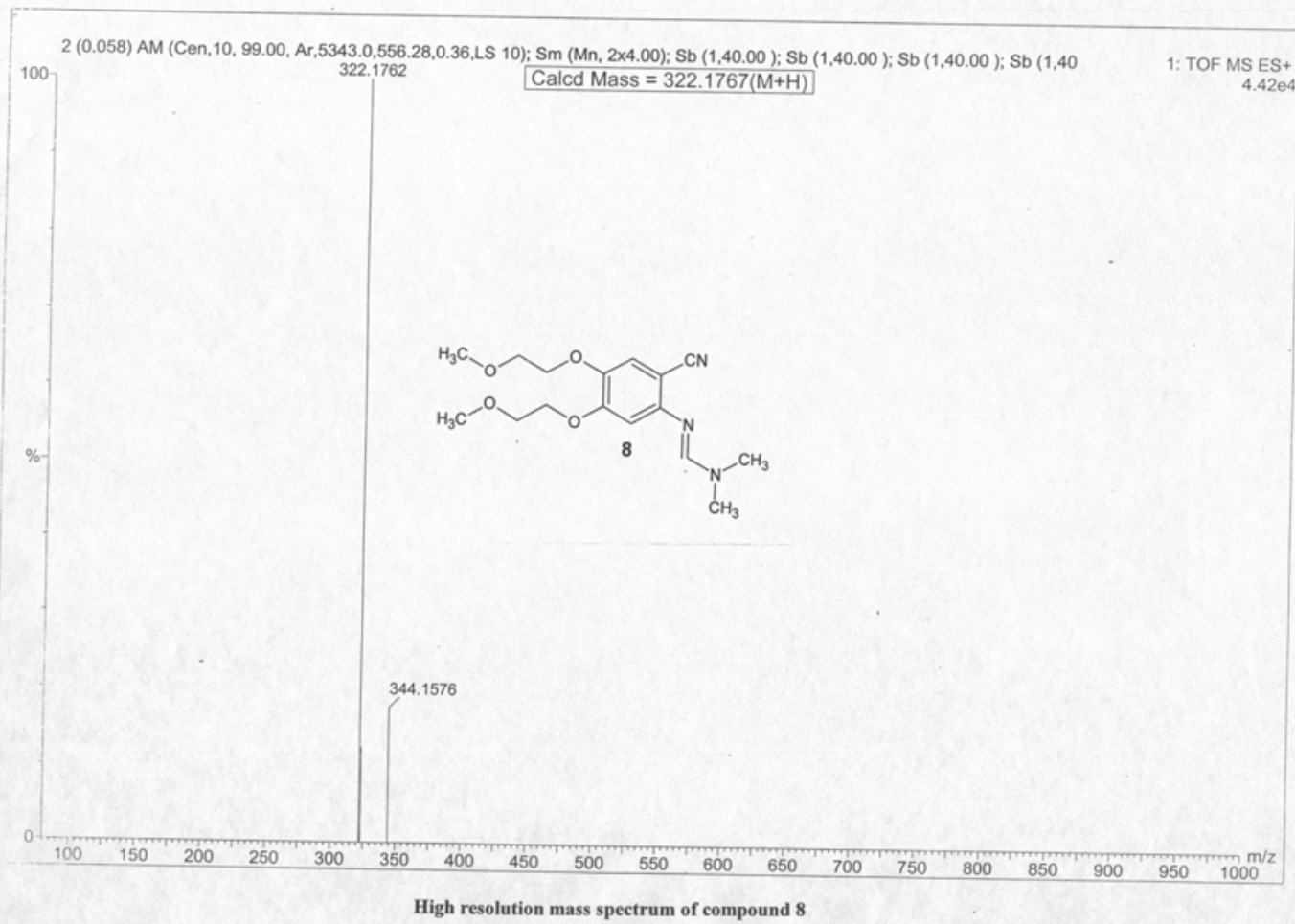

$\mathrm{S}_{6}$ 


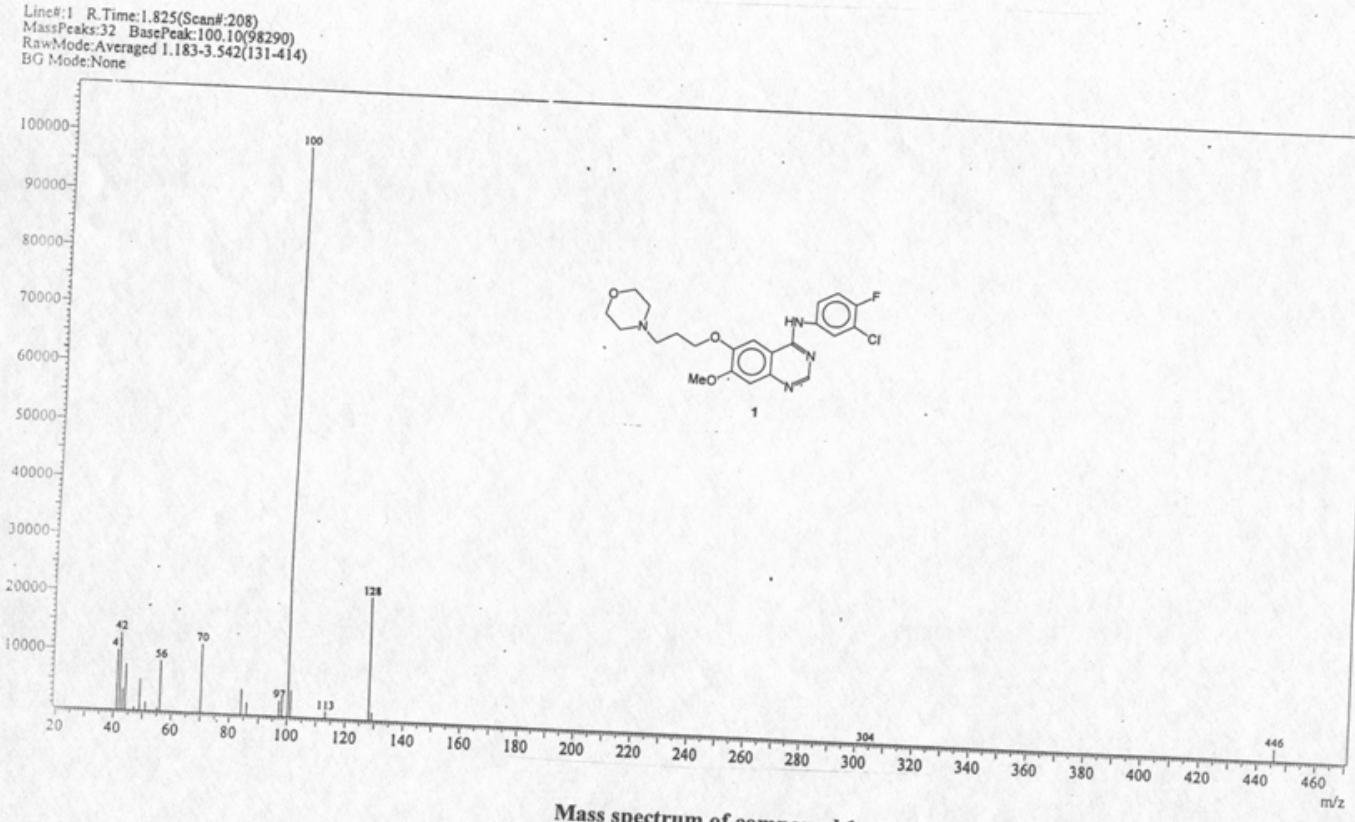

Mass spectrum of compound

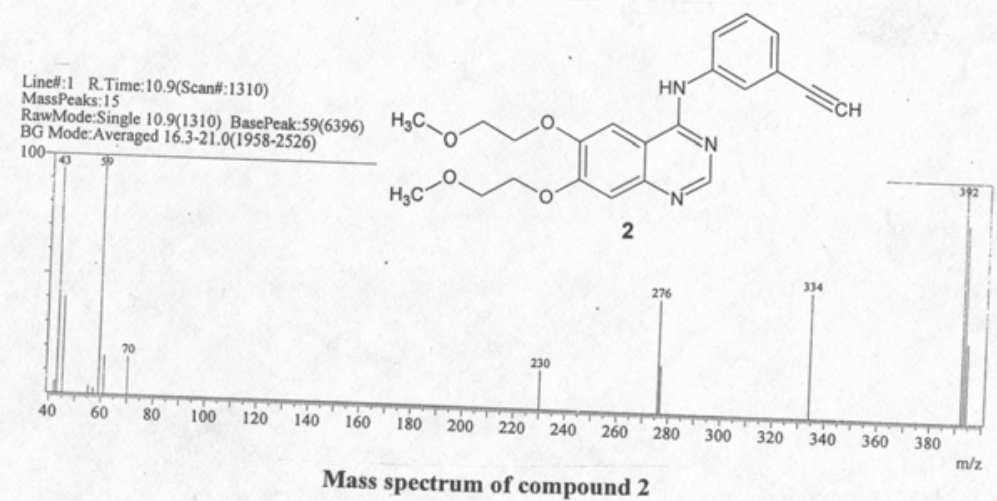

Mass spectrum of compound 2 

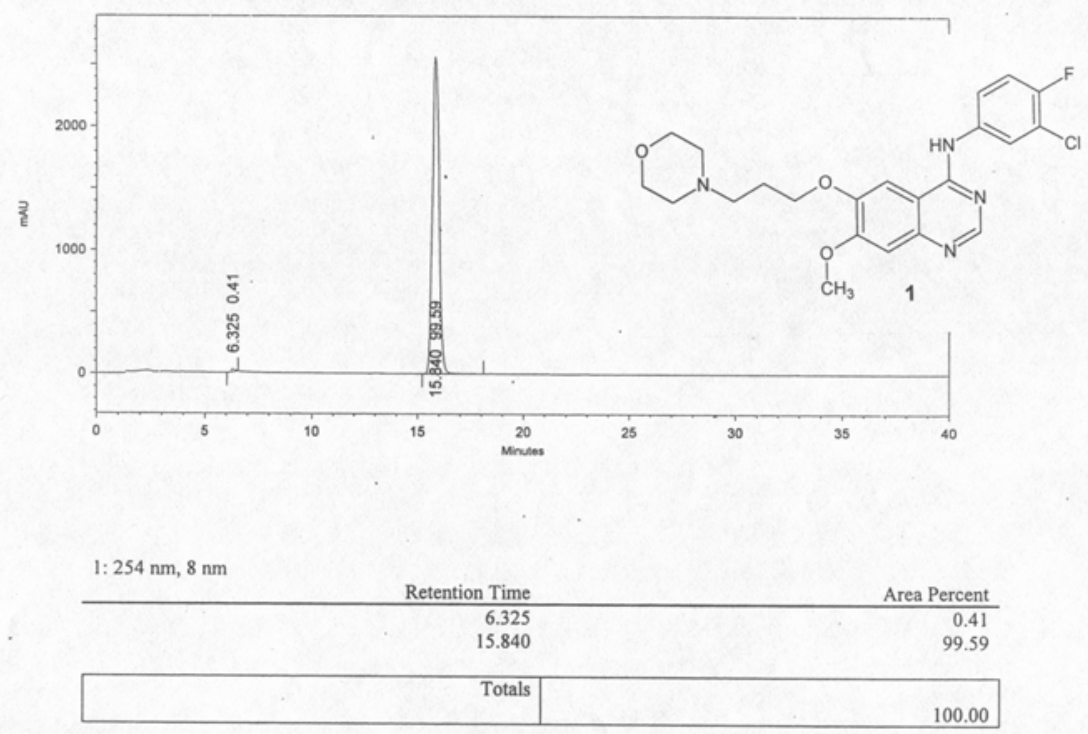

HPLC chromatogram of compound 1

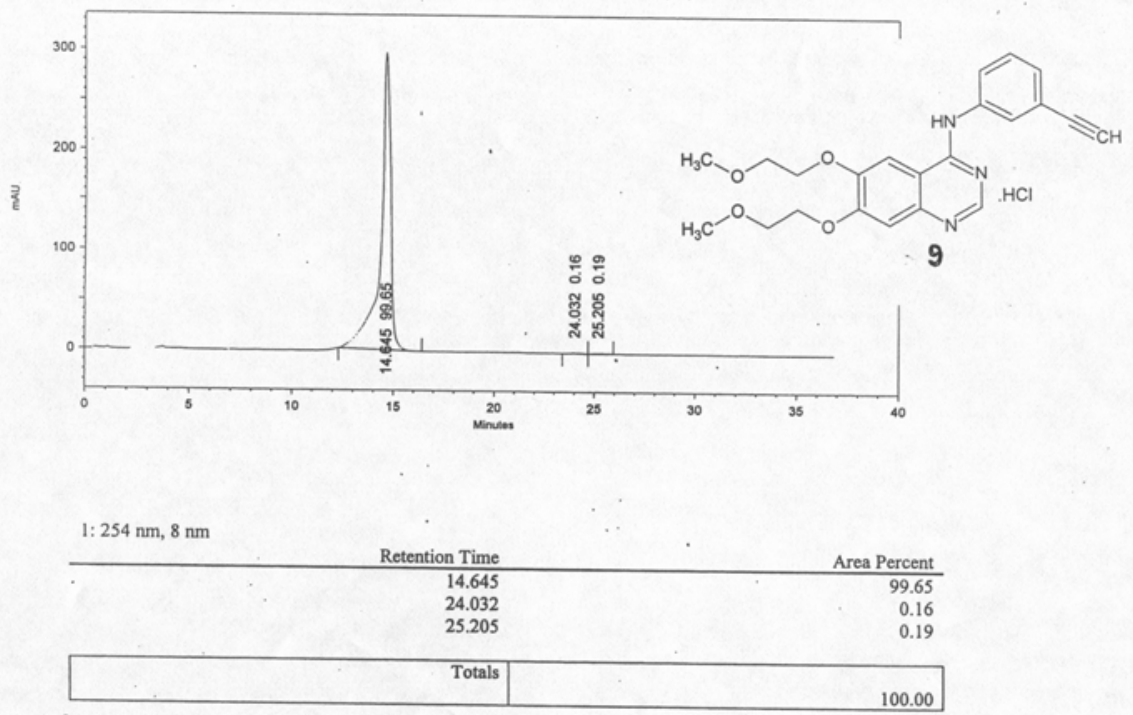

HPLC chromatogram of compound 9 